\title{
PANCREAS
}

\section{Extracellular calcium sensing receptor in human pancreatic cells}

\author{
G Z Rácz, Á Kittel, D Riccardi, R M Case, A C Elliott, G Varga
}

Gut 2002;51:705-711

\begin{abstract}
Background and aims: The extracellular calcium sensing receptor (CaR) plays a key role in the calcium homeostatic system and is therefore widely expressed in tissues involved in calcium metabolism. However, the CaR has also been identified in other tissues where its role is less clear. We have investigated the presence of the CaR in the human pancreas. Methods: Messenger RNA for the CaR was detected by reverse transcription-polymerase chain reaction and the protein was localised by immunostaining. CaR function was assayed in Capan-1 cells by measuring intracellular calcium and $\left[{ }^{3} \mathrm{H}\right]$ thymidine incorporation. Results: The receptor was highly expressed in human pancreatic ducts. It was also expressed in exocrine acinar cells, in islets of Langerhans, and in intrapancreatic nerves and blood vessels. The CaR was expressed in both normal and neoplastic human tissue samples but was detected in only one of five ductal adenocarcinoma cells lines examined. Experiments on the CaR expressing adenocarcinoma cell line Capan-1 showed that the CaR was functional and was linked to mobilisation of intracellular calcium. Stimulation of the CaR reduced Capan-1 cell proliferation.

Conclusions: We propose that the CaR may play multiple functional roles in the human pancreas. In particular, the $\mathrm{CaR}$ on the duct luminal membrane may monitor and regulate the $\mathrm{Ca}^{2+}$ concentration in pancreatic juice by triggering ductal electrolyte and fluid secretion. This could help to prevent precipitation of calcium salts in the duct lumen. The CaR may also help to regulate the proliferation of pancreatic ductal cells.
\end{abstract}

See end of article for authors' affiliations

Correspondence to: Dr AC Elliot, School of Biological Sciences (G38), University of Manchester, Manchester M13 9PT, UK; austin.elliot@ma.ac.uk and Dr G Varga, Institute of Experimental Medicine, $\mathrm{H}-1450$ Budapest, PO Box 67, Hungary; varga-g@koki.hu

Accepted for publication 28 March 2002

$\mathrm{T}$ he extracellular calcium sensing receptor $(\mathrm{CaR})$, first cloned from bovine parathyroid gland, ${ }^{1}$ is a key component in the calcium homeostatic system and is therefore expressed in tissues involved in calcium metabolism. However, CaRs have also been identified in a variety of other tissues. ${ }^{2}{ }^{3}$ In such tissues, CaRs have been suggested to have various roles, including regulation of vesicular secretion, cell proliferation, and differentiation. ${ }^{3}$ It is possible that in some of these tissues the CaR may serve primarily as a sensor of substances other than calcium, as the CaR can also be stimulated by polyvalent metal cations, organic polycations such as spermine, polylysine, protamine, and neomycin, ${ }^{4-6}$ and L-amino acids. ${ }^{7}$

We have recently reported the presence of the CaR in rat pancreatic acini and also on the luminal surface of rat pancreatic ducts. ${ }^{8}$ In isolated pancreatic ducts, stimulation of these luminal CaRs increased $\mathrm{HCO}_{3}^{-}$secretion. ${ }^{8}$ We therefore hypothesised that the CaR may monitor and regulate the $\mathrm{Ca}^{2+}$ concentration in rat pancreatic juice by triggering ductal electrolyte and fluid secretion. If a similar mechanism exists in humans, the CaR may help to prevent precipitation of calcium salts in the duct lumen, which can lead to pancreatic stone formation and even to pancreatitis. The CaR may also help to regulate the proliferation of pancreatic ductal cells.

The aims of the present study were therefore to determine the presence and localisation of CaR mRNA and protein in normal and malignant human pancreatic tissue samples, in pancreatic cancer cell lines, and in primary human pancreatic exocrine tissue cultures. We also investigated whether these receptors were functional and examined the effects of CaR activation on the proliferation of the pancreatic ductal adenocarcinoma cell line Capan-1. Our results showed that the CaR was expressed in both exocrine and endocrine pancreas in humans. The receptor was functional, and was highly expressed in human pancreatic ducts, suggesting that it may be an important regulator of both the physiology and cell biology of human pancreatic ductal cells.
Preliminary accounts of this work were presented to a joint meeting of the British and Hungarian Physiological Societies. ${ }^{9}$

\section{MATERIALS AND METHODS}

Tissue samples

Human pancreatic tissue samples were obtained from patients undergoing surgery for pancreatic neoplasia or chronic pancreatitis. Normal human pancreas samples were obtained either from patients whose pancreas was partially removed following trauma or from organ donors. All tissue samples were obtained after approval by the relevant local ethics committees. Specimens were snap frozen in liquid nitrogen and stored at $-70^{\circ} \mathrm{C}$ until use.

\section{Cell culture}

All human pancreatic ductal adenocarcinoma cell lines were obtained from the American Type Culture Collection. Capan-1 and Capan-2 are well differentiated cell lines derived respectively from 40 and 56 year old male Caucasians; MiaPaCa-2 is an undifferentiated cell line from a 65 year old male; PANC- 1 is a carcinoma of ductal origin from a 56 year old Caucasian male; and HPAF is a well differentiated but heterogeneous cell line. Capan-1 and Capan-2 cells were maintained in 90\% RPMI 1640 medium (Sigma, St Louis, Missouri, USA) while MiaPaCa-2 and HPAF cells were maintained in Dulbecco's modified Eagle's medium (Sigma). Both media were supplemented with $10 \%$ fetal calf serum,

Abbreviations: CaR, calcium sensing receptor; RT-PCR, reverse transcription-polymerase chain reaction; PBS, phosphate buffered saline; $\left[\mathrm{Ca}^{2+}\right]_{\mathrm{i}}$, intracellular free calcium ion concentration; DAB, diaminobenzidine; ORF, open reading frame; HBSS, Hepes buffered salt solution. 
$100 \mathrm{U} / \mathrm{ml}$ penicillin, and $100 \mu \mathrm{g} / \mathrm{ml}$ streptomycin (all from Sigma). Cells were routinely cultivated in a humidified atmosphere of $5 \% \mathrm{CO}_{2}$ and $95 \%$ air at $37^{\circ} \mathrm{C}$, and the culture medium was changed every three days.

\section{RNA preparation and RT-PCR}

Total RNA from tissue samples and adenocarcinoma cell lines was isolated using the monophasic reagent RNA Clean (Hybaid, Asford, UK). Total RNA samples prepared from normal human pancreatic primary cultures and from M540, an SV-40 immortalised human duct cell line, ${ }^{10}$ were obtained from Dr Francisco Real (Institut Municipal d'Investigacio Medica, Barcelona, Spain). For reverse transcriptionpolymerase chain reaction (RT-PCR), $5 \mu \mathrm{g}$ of total RNA from each sample were reverse transcribed using SuperScript II RNase $\mathrm{H}^{-}$reverse transcription (Life Technologies, San Diego, California, USA) using an oligo(dT) primer. The resulting first strand cDNA was then used for amplification with PCR primers based on the published human parathyroid CaR sequence. ${ }^{11}$ These primers, which were designed to span at least one intron to avoid false positives arising from amplification of genomic DNA contamination in RNA preparations, were CaR864-21F (5'-GGT CAG TTA TGC CTC CTC CAG-3'), forward primer from exon 3, and CaR2123-22R (5'-TTG TTA CAG GCA CTG GCA TCT G-3'), reverse primer from exon 7. High fidelity PCR reaction was performed using a mixture of Taq polymerase and $P f u$ polymerase (both from Promega, Madison, Wisconsin, USA), used according to the manufacturer's specification. After an initial denaturation at $95^{\circ} \mathrm{C}$ for two minutes, 30 cycles of amplification were performed. Samples were denatured at $96^{\circ} \mathrm{C}$ for 10 seconds, primers were annealed, and extension proceeded at $72^{\circ} \mathrm{C}$ for varying amounts of time depending on amplicon length (one minute per $1000 \mathrm{bp}$ ) in each cycle. In the first five cycles, primers were allowed to anneal at $58^{\circ} \mathrm{C}$ for 20 seconds. During the next 10 cycles, the initial annealing temperature was $58^{\circ} \mathrm{C}$, decreased by $0.8^{\circ} \mathrm{C}$ in each cycle; the initial annealing time was 20 seconds, increased by two seconds in each subsequent cycle. For the last 15 cycles, annealing took place at $50^{\circ} \mathrm{C}$ for 40 seconds. At the end of the 30 cycles, samples were incubated at $72^{\circ} \mathrm{C}$ for five minutes. The PCR products were resolved on agarose gels and their identity confirmed by high stringency Southern hybridisation of the products using a ${ }^{32} \mathrm{P}$ labelled cDNA probe corresponding to the complete coding region of the human pancreatic CaR (see below).

As an internal concentration reference for PCR experiments, we amplified mRNA for the acidic ribosomal protein XS13, which is constitutively expressed at the same level in normal, cancerous, and inflamed human pancreas and also in human pancreatic cell lines. ${ }^{12}$ The primers used to amplify XS13 were 5'-CTG GCT AAG TTG GTT GCT TT-3' (XS13FOR) and 5'-GCA GCT GAT CAA GAC TGG A-3' (XS13REV), and amplification was performed for 19 cycles with the following parameters: $94^{\circ} \mathrm{C}$ for 30 seconds; $58^{\circ} \mathrm{C}$ for 60 seconds; $72^{\circ} \mathrm{C}$ for 120 seconds.

\section{cDNA cloning and sequencing}

In order to clone the open reading frame (ORF) of the human pancreatic CaR, total RNA from normal human pancreas was reverse transcribed and the cDNA was used in PCR as described above. Primers were designed to span the ORF of the published sequence of human parathyroid CaR. These primers were HindIII SalI CaR179-22F (5'-TAT CAA GCT TCC GTC GAC GAC CAC CCA CAT TAC AAG TCT G-3') and XbaI NotI CaR3633-21R (5'-CAT GTC TAG AGC GGC CGC CTA GCC CAG TCT TCT CCT TCC-3'), incorporating restriction sites to facilitate cloning of the PCR product. A product of the expected size (3455 bp) was detected by agarose gel electrophoresis, excised, purified, digested with NotI and SalI (Promega), and then subcloned into the vector pBluescriptII KS (Stratagene, La Jolla,
California, USA) to give pBluescriptII KS hPCAR. Subsequently, the isolated cDNA clones were sequenced by cycle sequencing using vector specific and gene specific primers and analysed on an ABI Prism 310 Genetic Analyser.

\section{Quantitation of RT-PCR}

Relative quantitation of CaR mRNA in human pancreatic samples was carried out in two ways. Firstly, the intensities of the bands corresponding to the CaR PCR product were analysed by densitometry and normalised according to the intensity of the band obtained by amplifying XS13 from the same sample. Secondly, the CaR and XS13 amplicons were amplified together in one duplex reaction and the product band intensities compared by autoradiography following electrophoresis and Southern hybridisation. The primers CaR 2055-23F (5'-CTG CTT TGA GTG TGT GGA GTG TC-3') from exon 6 and CaR 3024-20R (5'-AGC CAC CTT GAA AGC GTG AG-3') from exon 7 were used to amplify CaR in the duplex reaction. The probes used for Southern hybridisation were the full length CaR cDNA (see above) for CaR and the labelled PCR product (see above) for XS13.

\section{Immunostaining}

Two different anti-CaR polyclonal antibodies were used to detect human CaR, one directed against amino acids 12-27 of rat CaR (Affinity Bioreagents, Golden, Colorado, USA) and the other directed against amino acids 214-235. ${ }^{13}$ The two antibodies gave essentially identical results in immunostaining experiments on both human pancreas cryosections and Capan-1 cells.

For electron microscopy, Capan-1 cells were rinsed in phosphate buffered saline (PBS) and fixed in $4 \%$ paraformaldehyde in PBS for 30 minutes at room temperature. Non-specific binding sites were blocked with $5 \%$ non-fat milk powder in PBS for 30 minutes. Cells were incubated with anti-CaR polyclonal antibody (1:200 dilution) overnight on a shaking plate at $4^{\circ} \mathrm{C}$. Antibody binding was detected using the $\mathrm{ABC}$ detection method, with diaminobenzidine (DAB) as chromogen (Vector Laboratories, Inc., Burlingame, California, USA), according to the manufacturer's instructions. After initial visualisation with a Nikon digital camera, cells were postfixed in $1 \%$ osmium tetroxide (Taab, Aldermaston, Berkshire, UK) in distilled water for 30 minutes, dehydrated, stained en block with uranyl acetate, and embedded in TAAB 812 (Taab). Ultrathin sections were examined using a Hitachi 2001 transmission electron microscope (Hitachi Corp., Japan).

For light microscopy, $5 \mu \mathrm{m}$ cryosections of normal and cancerous human pancreas tissue (see above) were cut so that each slide contained both normal and cancerous sections to facilitate direct comparison. After drying, sections were fixed in acetone at $-20^{\circ} \mathrm{C}$ for 10 minutes, followed by several rinses in PBS. Staining was performed in a Shandon immunostainer as described above for Capan-1 cells. Staining was visualised with DAB or with the Vector VIP substrate (Vector Laboratories Inc.), and sections were counterstained with haematoxylin for light microscopy. Pictures were obtained using a Nikon digital camera attached to a Nikon microscope with a $40 \times$ objective. Ductal structures were identified by their characteristic morphology, namely a layer of columnar epithelial cells surrounding an irregularly shaped lumen. Blood vessels were identified by their smooth lumen and the presence of the endothelial cell layer containing characteristically flattened nuclei. Negative control experiments were carried out either by omitting the primary antibody or by preabsorbing the primary antibody with the immunising peptide.

\section{Measurement of $\left[\mathrm{Ca}^{2+}\right]_{i}$}

Measurements of intracellular free $\mathrm{Ca}^{2+}\left(\left[\mathrm{Ca}^{2+}\right]_{\mathrm{i}}\right)$ were made using the $\mathrm{Ca}^{2+}$ sensitive fluorophore fura-2. Cultured Capan-1 cells grown on $24 \times 40 \mathrm{~mm}$ coverslips were washed three times 


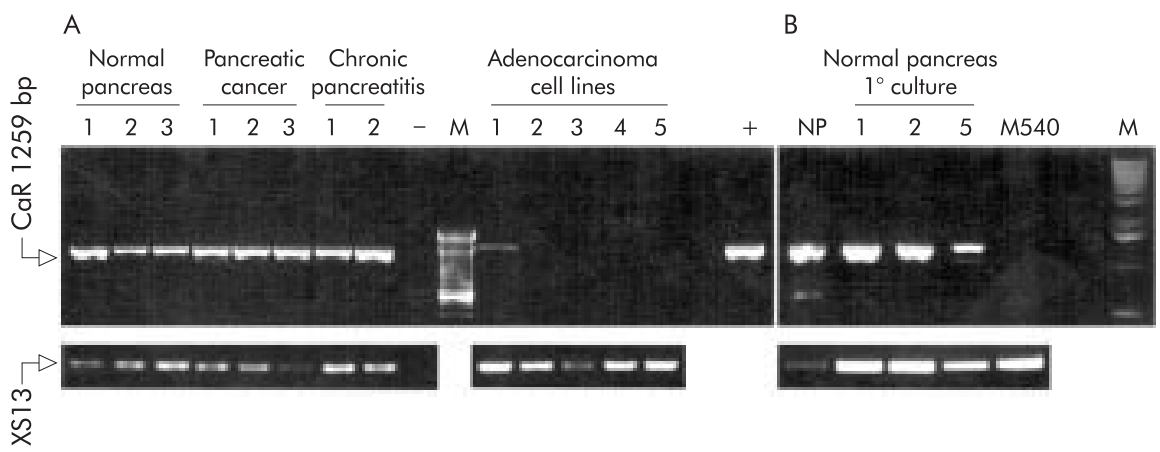

Figure 1 Detection of calcium sensing receptor (CaR) mRNA by reverse transcription-polymerase chain reaction (RT-PCR) in human pancreas, cultured pancreatic exocrine cells, and pancreatic adenocarcinoma cell lines. (A) CaR mRNA expression in normal human pancreas, pancreatic cancer, chronic pancreatitis, and the cell lines Capan-1 (1), Panc-1 (2), HPAF (3), MiaPaca-2 (4), and Capan-2 (5). M, 100 bp DNA ladder; -, negative control $\left(\mathrm{H}_{2} \mathrm{O}\right.$ replaced cDNA in the amplification); + , positive control (CaR plasmid). Arrow at the top is the 1259 bp CaR product while the lower arrow is the product of the constitutively expressed XS13 gene. (B) Detection of CaR mRNA in primary cultures of normal human pancreatic exocrine cells. NP, normal human pancreas; 1, 2, 5, days in culture before harvesting, RNA isolation, and RT-PCR analysis; M540, cell line obtained by immortalising cultured pancreatic exocrine cells with SV40; M, 1 kb DNA ladder.

with Hepes buffered salt solution (HBSS: $136.7 \mathrm{mM} \mathrm{NaCl}, 5$ $\mathrm{mM} \mathrm{KCl}, 2 \mathrm{mM} \mathrm{CaCl}, 2 \mathrm{mM} \mathrm{MgCl}, 0.34 \mathrm{mM} \mathrm{Na}_{2} \mathrm{HPO}_{4}, 0.44$ $\mathrm{mM} \mathrm{KH} \mathrm{PO}_{4}, 4 \mathrm{mM} \mathrm{NaHCO}, 5.55 \mathrm{mM}$ glucose, and $20 \mathrm{mM}$ Hepes at $\mathrm{pH} 7.4$ ) and loaded with $10 \mu \mathrm{M}$ fura-2 acetoxymethyl ester (Teflabs, Austin, Texas, USA) for 45 minutes at $37^{\circ} \mathrm{C}$ in a $95 \%$ air $/ 5 \% \mathrm{CO}_{2}$ atmosphere. After loading, cells were washed for 15 minutes by superfusion with HBSS in a thermostatically controlled chamber at $37^{\circ} \mathrm{C}$ on the stage of a Nikon Diaphot TMD inverted epifluorescence microscope (Nikon). Fluorescence from single cells was measured by microspectrofluorometry (D-104 Microscope Photometer, PTI, South Brunswick, New Jersey, USA) using a 40× Fluor objective (NA:0.85; Nikon). Emitted fura-2 fluorescence was measured at $520 \mathrm{~nm}$ during alternate excitation at 340 and $380 \mathrm{~nm}$. Known agonists of the CaR $\left(1 \mathrm{mM} \mathrm{Gd}^{3+}\right.$ or $4 \mathrm{mM}$ $\mathrm{Ca}^{2+}$ ) were applied by bath superfusion, typically for five minute periods. Changes in $\left[\mathrm{Ca}^{2+}\right]_{i}$ are presented as changes in the 340/380 fura-2 fluorescence ratio.

\section{$\left[{ }^{3} \mathrm{H}\right]$ thymidine incorporation assay}

Capan-1 cells were incubated in serum free Ham's Fl2 medium containing $0.5 \mathrm{mM} \mathrm{Ca}^{2+}$ for 24 hours and treated with CaR agonists. Incorporation of $\left[{ }^{3} \mathrm{H}\right]$ thymidine into DNA was measured after 24 hours of incubation with or without CaR agonists ( $1 \mathrm{mM} \mathrm{Gd} \mathrm{Cd}^{3+}$ or $\left.4 \mathrm{mM} \mathrm{Ca}^{2+}\right)$. Cells were exposed to $1 \mu \mathrm{Ci} / \mathrm{ml}\left[{ }^{3} \mathrm{H}\right]$ thymidine for one hour. They were then rinsed twice with ice cold PBS, precipitated using $10 \%$ trichloroacetic acid for 10 minutes, and air dried. The precipitate was dissolved in $400 \mu \mathrm{l}$ of $1 \mathrm{M} \mathrm{NaOH}$, and $100 \mu \mathrm{l}$ aliquots were mixed with $3 \mathrm{ml}$ of scintillation fluid (Opti Phase HiSafe II, Pharmacia). Radioactivity was determined by liquid scintillation spectrometry (Wallac 1409). Data are expressed as a percentage of $\left[{ }^{3} \mathrm{H}\right]$ thymidine incorporation into untreated control Capan-1 cells.

\section{Statistics}

All values are presented as mean (SEM). Comparison among groups was performed by analysis of variance (ANOVA).

\section{RESULTS}

\section{Expression of CaR mRNA}

We detected CaR mRNA by RT-PCR in normal human pancreas and in tissue samples from patients with both pancreatic neoplasia and chronic pancreatitis. We also observed CaR mRNA expression in the adenocarcinoma cell line Capan- 1 , but not in Panc-1, MiaPaca-2, Capan-2, or HPAF cells (fig 1A). Expression of CaR mRNA was also detected in primary cultures of normal human pancreatic exocrine cells. ${ }^{10}$ However, the level of CaR mRNA gradually decreased from culture day 0 to day 5 , and expression was undetectable in the M540 cell line, which was obtained by immortalising such primary human exocrine pancreatic cell cultures (fig lB). A similar reduction in CaR expression with time in culture has been noted in cultured bovine parathyroid cells where this reduction causes a dramatic loss of responsiveness to CaR stimulation. ${ }^{14}$

The initial RT-PCR experiments (fig l) did not suggest any dramatic differences in CaR mRNA levels between normal tissue samples and pancreatic cancer. However, CaR mRNA expression was clearly reduced or absent in the pancreatic adenocarcinoma cell lines. Expression of some other heptahelical G protein coupled receptors-for example, the sst2 somatostatin receptor-has been reported to be reduced in pancreatic cancer. ${ }^{15}$ We therefore quantitated the relative levels of CaR mRNA between normal and cancer tissue by RT-PCR by coamplifying cDNA for CaR with the constitutively expressed XS13 protein as an internal standard and quantifying the results by high stringency Southern blotting (fig 2). These experiments suggested that expression was not altered in the cancer tissue samples.

\section{cDNA sequencing}

We cloned a full length CaR cDNA from human pancreas as described in the methods section above. Sequencing revealed

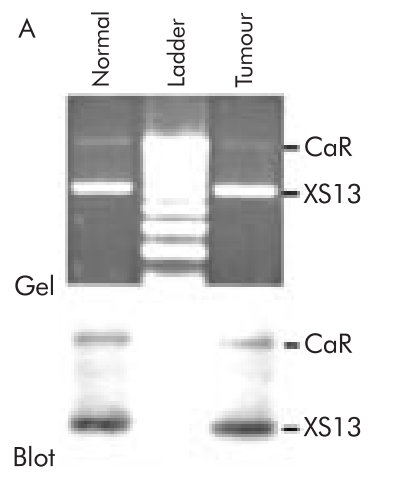

B

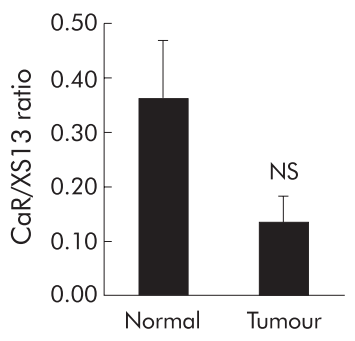

Figure 2 Quantitative reverse transcription-polymerase chain reaction (RT-PCR)/Southern blot analysis of calcium sensing receptor (CaR) expression in normal and malignant human pancreatic tissue samples. (A) Duplex PCR amplification of CaR and XS13 from CDNA samples from normal and cancerous human pancreas, together with Southern analysis of the same experiment (typical of five experiments). (B) Averaged data on the relative intensity of CaR (expressed as a fraction of the intensity of XS13 amplified from the corresponding sample) in normal and cancerous human pancreatic tissue samples. 

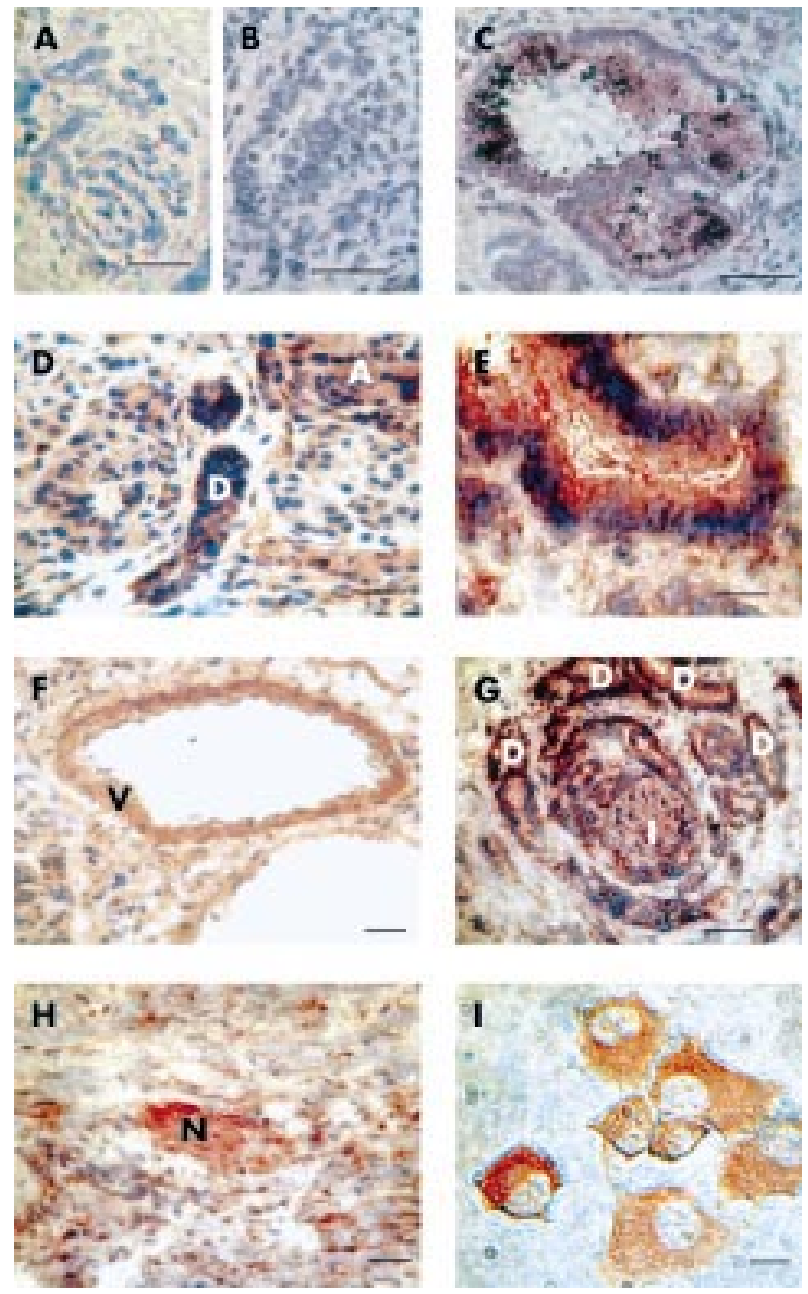

Figure 3 Immunohistochemistry for calcium sensing receptor (CaR) in normal human pancreas, pancreatic ductal adenocarcinoma, and Capan-1 cells. For human pancreatic samples, 5 m cryosections were incubated with primary anti-CaR antibody and staining was visualised with diaminobenzidine (DAB) (A, D-I) or the Vector VIP substrate $(B, C)$. Bars represent $200 \mu \mathrm{m}(A, D$ and $F-H)$ or $50 \mu \mathrm{m}$ $(B, C, E)$. (A) Control experiment performed in the absence of primary anti-CaR antibody (compare with (D) for example). (B) Preabsorption control (compare with (C)). (C, D, F) Sections from normal human pancreas (" $D$ " = pancreatic duct, " $A$ " =acinus, and " $V$ "=blood vessel). $(G, H)$ Sections from human pancreatic adenocarcinoma ("D"=abundant ductal structures, "I" =islet, and " $N$ "=nerve). Bars represent $200 \mu \mathrm{m}$. (E) Enlargement of a portion of the adenocarcinoma section shown in $(G)$ to emphasise heavy staining of ductal structure. (I) Detection of CaR protein in Capan-1 cells. Bar represents $10 \mu \mathrm{m}$.

that this cDNA had a nucleotide sequence identical to the CaR cDNA cloned from human parathyroid. ${ }^{11}$ This is in accord with the lack, so far, of multiple isoforms of the CaR (see Riccardi ${ }^{16}$ for discussion).

\section{Immunostaining}

Immunostaining was performed to localise the CaR protein in both normal and malignant human pancreas sections and in Capan-1 cells. In the normal pancreas CaR protein was detected in exocrine, endocrine, and excitable tissues (fig 3C, D). Strong staining was observed in pancreatic ducts, and fainter, but still clear, staining in acini. Staining of ducts and acini was not noticeably different in cancerous tissue samples.

Pancreatic islets also stained strongly for the CaR, confirming earlier results from rat pancreas. ${ }^{8}$ The CaR was also detected in intrapancreatic blood vessels. Prominent staining was seen on smooth muscle cells, with weaker staining on the
A

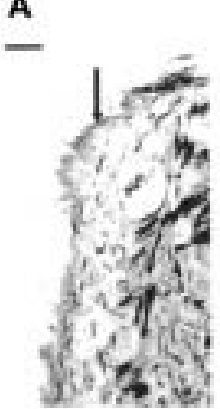

Figure 4 Immunostaining of calcium sensing receptor (CaR) at the cell surface of Capan-1 cells observed at the electron microscopic level. Diaminobenzidine precipitation (solid arrow) shows immunoreactivity for $\mathrm{CaR}(\mathrm{A})$. No staining was seen in the absence of primary antibody (arrow, B). Bars represent $0.15 \mu \mathrm{m}$.

endothelium ( fig 3C). Finally, intrapancreatic nerve terminals stained strongly for the CaR.

In both acinar and duct cells, CaR staining was seen in the cell cytoplasm, in agreement with previous results in rat pancreas. ${ }^{8}$ In rat pancreas, CaR was also detected on the apical cell membrane of duct cells. ${ }^{8}$ Examination of human ducts in cryosections at higher magnification gave qualified support to the idea that a similar apical membrane localisation may exist in human ducts. Thus staining could be seen up to the apical boundary of duct cells (see fig 3E), and in some ducts particularly heavy staining was observed at the apical cell boundary (fig 3C). However, given the heavy staining of the entire duct cell cytoplasm it was not possible to determine the presence of the CaR on the duct apical membrane with complete certainty.

We were able to detect membrane staining for the CaR in the Capan-1 cell line using immuno-electron microscopy techniques (fig 4). However, Capan-1 cells used in this study were not polarised, and this result does not therefore shed any light on the basolateral or apical localisation of the CaR in human ducts.

\section{Intracellular free calcium measurements}

To study whether CaRs in the pancreas were functional, we measured the increase in $\left[\mathrm{Ca}^{2+}\right]_{i}$ evoked by $\mathrm{CaR}$ agonists in fura-2 loaded Capan-1 cells. Both $\mathrm{Ca}^{2+}$ and $\mathrm{Gd}^{3+}$ were used as CaR agonists, the latter because it is non-permeable. Both $\mathrm{Ca}^{2+}$ $(4 \mathrm{mM})$ and $\mathrm{Gd}^{3+}(1 \mathrm{mM})$ caused a rapid transient elevation of $\left[\mathrm{Ca}^{2+}\right]_{\mathrm{i}}$ (fig $\left.5 \mathrm{~A}, \mathrm{~B}\right)$. This is consistent with results observed in other cell lines endogenously or heterogeneously expressing the CaR, and strongly suggests that the CaR in human pancreas is coupled to $\mathrm{Gq} /$ phospholipase C.

\section{Cell proliferation}

In several cell types, changes in extracellular calcium have been shown to alter cellular proliferation ${ }^{17-19}$ and CaRs have been implicated in these effects. Incorporation of $\left[{ }^{3} \mathrm{H}\right]$ thymidine was therefore used to examine the effect of CaR agonists on the proliferation of Capan-1 cells. Both $1 \mathrm{mM} \mathrm{Gd}^{3+}$ and $4 \mathrm{mM} \mathrm{Ca}^{2+}$ caused a significant although only modest (approximately 20\%) inhibition of DNA synthesis (fig 6). Mean values for $\left[{ }^{3} \mathrm{H}\right]$ thymidine incorporation were $100(4) \%$ $(\mathrm{n}=19)$ for controls, $81(4) \%$ for $\mathrm{Gd}^{3+}$, and $75(7) \%$ for $4 \mathrm{mM}$ $\mathrm{Ca}^{2+}$ (both $\mathrm{n}=17$; both values statistically different from control by ANOVA, $\mathrm{p}<0.05$ for $\mathrm{Gd}^{3+}$ and $\mathrm{p}<0.01$ for $4 \mathrm{mM} \mathrm{Ca}^{2+}$ ).

\section{DISCUSSION}

The present study provides the first evidence for the presence of CaR in human exocrine pancreas. Expression of mRNA for the CaR was detected by RT-PCR techniques, and immunohistochemistry showed that the CaR was expressed in both acinar and duct cells, as well as in various non-exocrine cells, 
A

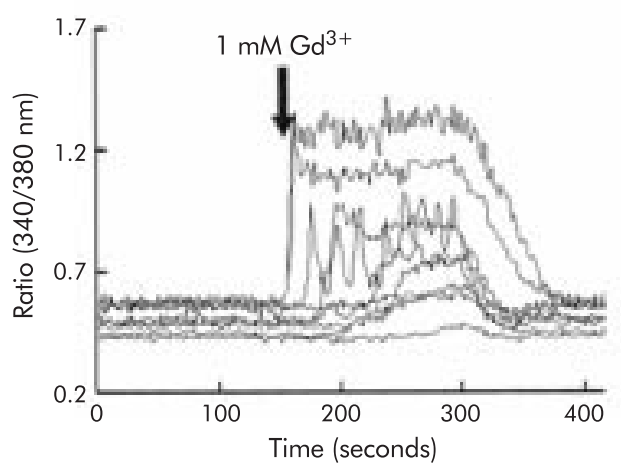

B

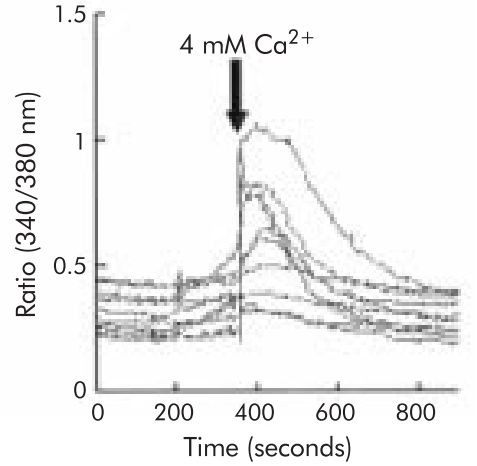

Figure 5 Effect of $1 \mathrm{mM} \mathrm{Gd}{ }^{3+}(A)$ and $4 \mathrm{mM}$ extracellular $\mathrm{Ca}^{2+}$ (B) on intracellular free calcium concentration ([Ca $\left.{ }^{2+}\right]_{\mathrm{i}}$ ) in 10 Capan-1 cells in a single microscope field. Cultured Capan-1 cells grown on coverslips were loaded with $10 \mu M$ fura-2 acetoxymethyl ester. Calcium sensing receptor agonists were applied by bath superfusion, and emitted fura-2 fluorescence was measured at $520 \mathrm{~nm}$ during alternate excitation at 340 and $380 \mathrm{~nm}$. Changes in $\left[\mathrm{Ca}^{2+}\right]_{i}$ are presented as changes in the $340 / 380$ fluorescence ratio.

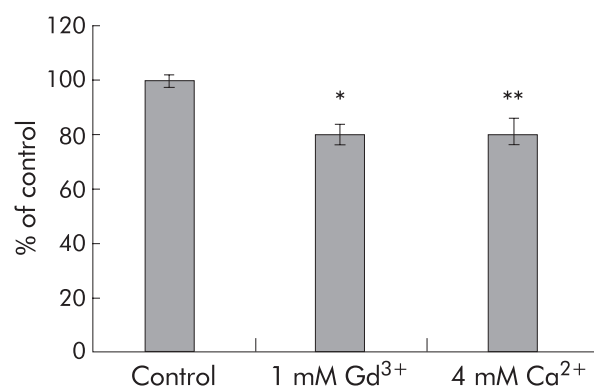

Figure 6 Effects of calcium sensing receptor agonists on proliferation of Capan-1 cells. Cells were initially incubated in serum free medium with low $(0.5 \mathrm{mM})$ calcium for 24 hours, then left untreated or treated with $1 \mathrm{mM} \mathrm{Gd}^{3+}$ or $4 \mathrm{mM} \mathrm{Ca}^{2+}$ for 24 hours, and finally pulse labelled for one hour with ${ }^{3} \mathrm{H}$ thymidine. Incorporated radioactivity was measured by liquid scintillation counting. Results are presented as per cent of radioactivity incorporated into untreated control cells (SEM). * $p<0.05$, ** $p<0.01$

including islet cells, blood vessels, and nerves. This suggests that the CaR could potentially play multiple functional roles in the human pancreas.

\section{Possible role of the CaR in human pancreatic exocrine physiology}

The site of highest CaR expression in the human pancreas was in exocrine ducts. This is in line with an earlier study demonstrating a similar distribution in CaR protein in rat pancreas. ${ }^{8}$ In rat pancreas, we found that the CaR was present on the duct luminal membrane and that stimulation of luminal CaRs increased ductal $\mathrm{HCO}_{3}^{-}$(and hence presumably also fluid) secretion. We speculated that this might represent a feedback system to activate ductal fluid secretion in response to elevated extracellular (luminal) $\left[\mathrm{Ca}^{2+}\right]$, thereby reducing the risk of calcium salt precipitation that could lead to pancreatic stone formation and even to pancreatitis. Whether such a homeostatic mechanism exists in humans is unknown. It is tempting to speculate that it does, given the high level of CaR protein expressed in human pancreatic ducts and the relative rarity of pancreatic stone formation, despite the pancreatic juice being an alkaline environment containing large amounts of $\mathrm{Ca}^{2+}$. However, other mechanisms have been suggested to explain this paradoxical rarity of pancreatic stones, including the presence in pancreatic secretion of the $\mathrm{CaCO}_{3}$ crystallisation inhibitor lithostatine..$^{20}$

The role of the CaR in acinar cells also remains unclear. As in the rat, CaR immunostaining was observed in the cytosol of human acinar cells. ${ }^{8}$ However, this does not preclude the presence of the $\mathrm{CaR}$ on the plasma membrane (see Bruce and colleagues $^{8}$ for discussion of this point). By analogy with the rat data, it seems plausible that at least some CaR might be present on the plasma membrane in human acinar cells.

\section{Expression of CaRs in non-exocrine cells}

We observed CaR expression in human islets of Langerhans and in intrapancreatic nerves and blood vessels. Detection of CaR in human islets is in accord with the recent work of Goebel and colleagues. ${ }^{21}$ Interestingly, Goebel et al did not detect CaR expression in exocrine tissue. However, it is worth noting that no ducts were visible in the pancreatic sections published in their paper, while we found ducts to be the predominant site of CaR protein expression. We also observed faint but clearly visible CaR staining on pancreatic acini, which was not detected by Goebel et al. Possible explanations for this difference could relate to the sensitivity of the different methods used for sample preparation and fixation or to the different antisera used.

We also detected the CaR protein in intrapancreatic nerves and blood vessels. The presence of CaR on nerve terminals is reminiscent of similar results reported for nerves within the duodenum and kidney. ${ }^{22}{ }^{23}$ In these two organs it has been suggested that changes in interstitial $\left[\mathrm{Ca}^{2+}\right]$ might alter organ blood flow via local reflexes controlling the intraorgan vasculature. ${ }^{24}$ Staining of intrapancreatic nerves might therefore imply operation of a similar mechanism in the human pancreas.

\section{Capan-1 cells as a model for normal human duct cell function}

Systematic functional studies on normal human pancreatic exocrine cells are virtually impossible because of the difficulty of obtaining tissue to study. However, human pancreatic adenocarcinoma cell lines have been widely used as model systems to study pancreatic physiology and pathophysiology, including cell proliferation. A recurring question with such cell lines is how closely they reproduce the physiology of parent tissue. We therefore screened for CaR expression in several well known pancreatic cell lines. Among the cell lines studied, the well differentiated Capan-l cell line showed the highest relative level of CaR mRNA, and the presence of the CaR protein in this cell line, including on the cell surface, was confirmed by immunocytochemistry at both the light microscopic and electron microscopic levels. Expression of the CaR in Capan-l cells was also confirmed by functional studies, with the transient increase in $\left[\mathrm{Ca}^{2+}\right]_{i}$ in response to stimulation with CaR agonists suggesting CaRs were coupled via $\mathrm{G}$ proteins to phospholipase $\mathrm{C}$, as is typical for this 
receptor. ${ }^{3}$ Our work suggests that Capan- 1 cells may prove a fruitful model for studying the physiology of the CaR in human pancreas. Capan-I cells have many advantages as a cell model for human pancreatic duct as they can be grown as a polarised monolayer and express ion transporters, ion channels, and receptors which have been characterised as components of the ductal secretory mechanism and its regulatory apparatus in native rodent duct cells. ${ }^{25-27}$

\section{CaR expression in pancreatic disease}

Our immunohistochemical studies demonstrated similar CaR staining of exocrine tissue in pancreatic ductal adenocarcinoma and normal human pancreas. Quantitative RT-PCR and Southern blotting confirmed that neoplastic transformation does not consistently involve up- or downregulation of CaR expression. However, CaR expression was clearly reduced or absent in pancreatic adenocarcinoma cell lines, and the results in fig 6 show that the CaR can influence cell proliferation in duct cells. It is thus possible that the CaR could be involved in negatively regulating duct cell proliferation, in a similar fashion to what has been suggested for somatostatin receptors. ${ }^{15}$ There are a number of lines of evidence implicating the CaR in the regulation of cell proliferation and differentiation in other systems. Thus increasing extracellular $\mathrm{Ca}^{2+}$ concentration has been reported to have antiproliferative differentiation promoting effects in several epithelial cell types ${ }^{28-32}$ although elevated extracellular $\mathrm{Ca}^{2+}$ acting via the $\mathrm{CaR}$ induces proliferation of human fibroblasts. ${ }^{17}{ }^{33}$ In our study Capan-1 cell proliferation was clearly reduced by elevated extracellular $\mathrm{Ca}^{2+}$ or $\mathrm{Gd}^{3+}$. The similar effects of the two cations clearly imply that this decrease in proliferation was a consequence of CaR activation. The decrease in proliferation was not dramatic but this could be due to the low level of CaR expression by Capan-l cells.

Pancreatic ductal adenocarcinoma is a highly aggressive cancer and currently has a very poor survival rate. A detailed understanding of the cell signalling mechanisms which control the growth of pancreatic tumour cells is seen as a key stage in the development of new therapies to tackle the disease. ${ }^{34}$ Heptahelical G protein coupled receptors for regulatory peptides that stimulate cell proliferation are present in many pancreatic cancer cell lines, suggesting that antagonists of these receptors might ultimately prove useful in therapy. ${ }^{35}$ Our work shows that CaRs, when expressed in pancreatic cancer cells, may play a role in reducing proliferation. Although the CaR was expressed in only one of the established pancreatic cancer cell lines examined, it was clearly expressed in all of the human neoplastic tissue samples we tested. The role of the CaR in the human pancreatic duct cell clearly bears further investigation, which should be aided by the fact that selective activators of the CaR have been described. ${ }^{36}$

\section{SUMMARY}

In summary, our results show that functional CaRs are present in multiple cell types in human pancreas, raising several possible roles for CaRs in human pancreatic physiology and pathophysiology. However, further studies are required to elucidate the mechanisms responsible for their actions on cell proliferation and other cellular functions. Finally, the adenocarcinoma cell line Capan-1 may prove a useful model system for studying the role of the CaR in human pancreatic duct cell function.

\section{ACKNOWLEDGEMENTS}

This work was funded by the Wellcome Trust, the INCO programme of the European Commission, and the Hungarian National Committee for Technological Development. We are grateful to Dr Paco Real, Institut Municipal d'Investigacio Medica, Barcelona, Spain, for RNA samples from human primary cultures and the M540 cell line.

\section{Authors' affiliations}

G Z Rácz, Á Kittel, G Varga, Institute of Experimental Medicine, Hungarian Academy of Sciences, H-1083 Budapest, Hungary

D Riccardi, R M Case, A C Elliott, School of Biological Sciences, University of Manchester, Manchester M13 9PT, UK

\section{REFERENCES}

1 Brown EM, Gamba G, Riccardi D, et al. Cloning and characterization of an extracellular $\mathrm{Ca}(2+)$-sensing receptor from bovine parathyroid. Nature 1993;366:575-80.

2 Riccardi D. Calcium ions as extracellular, first messengers. Z Kardiol 2000;89(suppl 2):9-14.

3 Brown EM, MacLeod RJ. Extracellular calcium sensing and extracellular calcium signaling. Physiol Rev 2001;81:239-97.

4 Brown EM. Extracellular Ca2+ sensing, regulation of parathyroid cell function, and role of $\mathrm{Ca} 2+$ and other ions as extracellular (first) messengers. Physiol Rev 1991;71:371-411.

5 Brown EM, Katz C, Butters R, et al. Polyarginine, polylysine, and protamine mimic the effects of high extracellular calcium concentrations on dispersed bovine parathyroid cells. J Bone Miner Res 1991:6:1217-25

6 Quinn SJ, Ye CP, Diaz R, et al. The Ca2+-sensing receptor: a target for polyamines. Am J Physiol 1997;273:C1315-23.

7 Conigrave AD, Quinn SJ, Brown EM. L-amino acid sensing by the extracellular Ca2+-sensing receptor. Proc Natl Acad Sci USA 2000;97:4814-19.

8 Bruce JI, Yang X, Ferguson CJ, et al. Molecular and functional identification of a Ca2+ (polyvalent cation)-sensing receptor in rat pancreas. J Biol Chem 1999;274:20561-8.

9 Rácz G, Kittel Á, Riccardi D, et al. Identification of calcium-sensing receptors in human pancreas. J Physiol 2000;526P:178P.

10 Vila MR, Lloreta J, Real FX. Normal human pancreas cultures display functional ductal characteristics. Lab Invest 1994;71:423-31.

11 Garrett JE, Capuano IV, Hammerland LG, et al. Molecular cloning and functional expression of human parathyroid calcium receptor cDNAs. J Biol Chem 1995;270:12919-25.

12 Wallrapp C, Muller-Pillasch F, Solinas-Toldo S, et al. Characterization of a high copy number amplification at 6 q24 in pancreatic cancer identifies c-myb as a candidate oncogene. Cancer Res 1997;57:3135-9.

13 Riccardi D, Traebert M, Ward DT, et al. Dietary phosphate and parathyroid hormone alter the expression of the calcium-sensing receptor $(\mathrm{CaR})$ and the $\mathrm{Na}^{+}$-dependent $\mathrm{Pi}$ transporter $(\mathrm{NaPi}-2)$ in the rat proximal tubule. Pflugers Arch 2000;441:379-87.

14 Mithal A, Kifor O, Kifor I, et al. The reduced responsiveness of cultured bovine parathyroid cells to extracellular $\mathrm{Ca} 2+$ is associated with marked reduction in the expression of extracellular $\mathrm{Ca}(2+)$-sensing receptor messenger ribonucleic acid and protein. Endocrinology 1995; 136:3087-92.

15 Buscail L, Saint-Laurent N, Chastre E, et al. Loss of sst2 somatostatin receptor gene expression in human pancreatic and colorectal cancer. Cancer Res 1996;56:1823-7.

16 Riccardi D. Cell surface, $\mathrm{Ca}^{2+}$ (cation) sensing receptor(s): one or many? Cell Calcium 1999;26:77-83

17 McNeil SE, Hobson SA, Nipper V, et al. Functional calcium-sensing receptors in rat fibroblasts are required for activation of SRC kinase and mitogen-activated protein kinase in response to extracellular calcium. $J$ Biol Chem 1998;273:1114-20.

18 Hulla W, Kallay E, Krugluger W, et al. Growth control of human colon-adenocarcinoma-derived Caco-2 cells by vitamin-D compounds and extracellular calcium in vitro: relation to c-myc-oncogene and vitamin-D-receptor expression. Int J Cancer 1995;62:71 1-16.

19 Yamaguchi T, Chattopadhyay N, Kifor O, et al. Mouse osteoblastic cell line (MC3T3-E1) expresses extracellular calcium (Ca2+o)-sensing receptor and its agonists stimulate chemotaxis and proliferation of MC3T3-E 1 cells. J Bone Miner Res 1998;13:1530-8.

20 De Caro A, Multigner L, Lafont $\mathrm{H}$, et al. The molecular characteristics of a human pancreatic acidic phosphoprotein that inhibits calcium carbonate crystal growth. Biochem J 1984;222:669-77.

21 Goebel SU, Peghini PL, Goldsmith PK, et al. Expression of the calcium-sensing receptor in gastrinomas. J Clin Endocrinol Metab 2000;85:4131-7.

22 Chattopadhyay N, Cheng I, Rogers K, et al. Identification and localization of extracellular $\mathrm{Ca}(2+)$-sensing receptor in rat intestine. Am J Physiol 1998;274:G122-30

23 Riccardi D, Hall AE, Chattopadhyay N, et al. Localization of the extracellular $\mathrm{Ca} 2+$ /polyvalent cation-sensing protein in rat kidney. Am J Physiol 1998;274:F61 1-22.

24 Mupanomunda MM, Tian B, Ishioka N, et al. Renal interstitial $\mathrm{Ca}^{2+}$. $\mathrm{Am}$ J Physiol 2000;278:F644-9.

25 Cheng HS, Leung PY, Cheng Chew SB, et al. Concurrent and independent $\mathrm{HCO}_{3}{ }^{-}$and $\mathrm{Cl}^{-}$secretion in a human pancreatic duct cell line (CAPAN-1). J Membr Biol 1998;164:155-67.

26 Cheng HS, Wong WS, Chan KT, et al. Modulation of $\mathrm{Ca}^{2+}$-dependent anion secretion by protein kinase $C$ in normal and cystic fibrosis pancreatic duct cells. Biochim Biophys Acta 1999;1418:31-8.

27 Shumaker $\mathrm{H}$, Amlal $\mathrm{H}$, Frizzell R, et al. CFTR drives $\mathrm{Na}^{+}-\mathrm{nHCO}_{3}{ }^{-}$ cotransport in pancreatic duct cells: a basis for defective $\mathrm{HCO}_{3}{ }^{-}$secretion in CF. Am J Physiol 1999;276:C16-25. 
28 Yuspa SH, Kilkenny AE, Steinert PM, et al. Expression of murine epidermal differentiation markers is tightly regulated by restricted extracellular calcium concentrations in vitro. J Cell Biol 1989:109:1207-17

29 Ochieng J, Tahin QS, Booth CC, et al. Buffering of intracellular calcium in response to increased extracellular levels in mortal, immortal, and transformed human breast epithelial cells. J Cell Biochem $1991 ; 46: 250-4$.

30 Black BL, Smith JE. Regulation of goblet cell differentiation by calcium in embryonic chick intestine. FASEB J 1989:3:2653-9.

31 Buras RR, Shabahang $M$, Davoodi F, et al. The effect of extracellular calcium on colonocytes: evidence for differential responsiveness based upon degree of cell differentiation. Cell Prolif 1995;28:245-62.

32 Oda $Y$, Tu CL, Chang W, et al. The calcium sensing receptor and its alternatively spliced form in murine epidermal differentiation. J Biol Chem 2000;275: $1183-90$

33 Huang S, Maher VM, McCormick JJ. Extracellular $\mathrm{Ca}^{2+}$ stimulates the activation of mitogen-activated protein kinase and cell growth in human fibroblasts. Biochem J 1995:310:881-5.

34 Brand RE, Tempero MA. Pancreatic cancer. Curr Opin Oncol 1998; 10:362-6

35 Ryder NM, Guha S, Hines OJ, et al. G protein-coupled receptor signaling in human pancreatic ductal cancer cells: neurotensin responsiveness and mitogenic stimulation. J Cell Physiol 2001; 186:53-64

36 Nemeth EF, Steffey ME, Hammerland LG, et al. Calcimimetics with potent and selective activity on the parathyroid calcium receptor. Proc Natl Acad Sci USA 1998;95:4040-5.

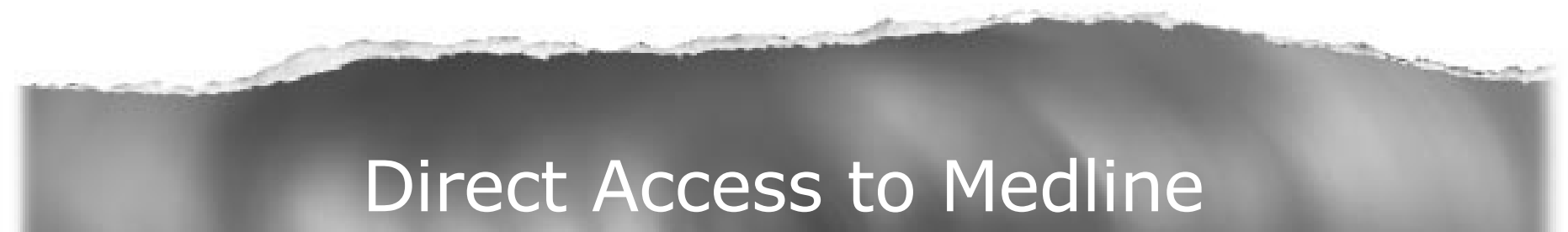

\section{Medline}

Link to Medline from the homepage and get straight into the National Library of Medicine's premier bibliographic database. Medline allows you to search across 9 million records of bibliographic citations and author abstracts from approximately 3,900 current biomedical journals.

\section{www.gutjnl.com}

